\title{
Identifying Potential Factors of Childbearing in Bangladesh
}

\author{
Md. Asaduzzaman (Corresponding author) \\ Institute of Statistical Research and Training (ISRT) \\ University of Dhaka, Dhaka 1000 \\ Bangladesh \\ E-mail: asad@isrt.ac.bd \\ Md. Hasinur Rahaman Khan \\ Institute of Statistical Research and Training (ISRT) \\ University of Dhaka, Dhaka 1000 \\ Bangladesh \\ E-mail: hasinur@isrt.ac.bd
}

\begin{abstract}
This paper aims to identify different potential factors associated with childbearing pattern among the ever-married women in Bangladesh. Childbearing pattern is directly related to fertility level and rapid population growth is the major consequence of more childbearing. Bearing more children affects adversely on social and economic opportunities and produces substantial risks to the health of mothers and children. Bangladesh Demographic Health Survey data 1999-2000 and 2004 have been used for this study. First bi-variate analysis method is carried out to identify different factors associated with childbearing. Then generalized linear modelling approach has been performed to quantify the simultaneous effect of key socio-economic and demographic factors. Our primary findings show that childbearing varied tremendously by education level and age at first marriage. From the generalized linear model analysis, mother's age group, types of place of residence, division, media exposure are found to be significantly associated with bearing more children among the ever-married women in Bangladesh. These findings suggest that government should continue its effort to ensure higher education for females and to promote to delay age at marriage.
\end{abstract}

Keywords: Childbearing, Socio-economic factor, Demographic factor, BDHS data

\section{Introduction}

Bearing more children is a common phenomenon among the women in the least developed countries like Bangladesh. The women in Bangladesh become mother at their very early ages with the large majority of women started bearing children before they reach at the age of twenty (Singh, 1998). For the lack of education and awareness, poverty, marriage at early ages they used to bear children year after year. Consequently their family size increases and population grows rapidly. Childbearing at the young ages consequences a greater risk to maternal mortality and child mortality to the mother and the child respectively (Manken et al., 2003). It also inclines to restrict the educational and economic opportunities for all. Another impact of more childbearing is the malnutrition to mother and children. The childbearing tendency reflects the extent of contraceptive practice in a country. In Bangladesh, the pill, IUD, female sterilization, injectables and condom are widely known methods of contraception. The use of these methods is increased over the last twenty-five years (Mitra et al., 2000; Mitra et al., 2004). Perhaps this is the main reason of declining fertility in Bangladesh.

Bangladesh is a tiny land and one of the most densely populated countries in the world. The government has taken all necessary steps to decrease the fertility level. Women in both rural and urban areas are becoming conscious and accepting small family norm. Although fertility has declined over past twenty years, it has been observed that most of the decrease happened to older age cohort, not the younger age group (Mitra et al., 2000; Mitra et al., 2004). During 1993-2004 there was a very little change in age specific fertility and childbearing pattern (Fig. 1 and Fig. 2). 
Therefore, it still requires understanding the nature and trend of the determinants of fertility to keep the rate low. Concerning studies on overall childbearing pattern very few articles have been found in the literature. Islam (1999) and Nahar and Min (2008) studied the trends and determinants of adolescent childbearing in Bangladesh. The effects of childbearing on survival of adult women in Bangladesh was studied by Manken et al. (2003) while Schuler et al. (2006) tried to discover the potential effect of intervention programmes on the timing of marriage and childbearing among rural families in Bangladesh. In terms of determining the factors of fertility in Bangladesh a number of studies has been performed (Rob, 1990; Islam and Islam, 1993; Islam et al., 1998). Some studies have also been performed to examine the factors related to desire for more childbearing in Bangladesh (Asaduzzaman and Ullah, 2003). Most of these studies have been used only bi-variate analysis to identify the related factors of fertility and relatively very little is know about the trend and potential factors related to childbearing. Also very little sophisticated and statistically sound methods have been performed for analysis.

In this paper, we first use bi-variate analysis method to identify initial factors related to childbearing. Then a generalized linear modeling (GLM) approach has been used to quantify potential socio-economic and demographic factors related to more childbearing in Bangladesh. Bangladesh demographic and health survey data have been used for this study. A number of candidate factors have been considered initially. Among the infant factors mother's age group, educational level, types of place of residence, age at first marriage, division, media exposure have been identified the most significant factors of childbearing in Bangladesh. Using two consecutive survey data, we also compare the estimated coefficients of different factors.

\section{Data and Methods}

\subsection{Data Source}

Bangladesh Demographic and Health Survey (BDHS) 1999-2000 and 2004 data have been used for this study. In rural areas, thanas are divided into unions and then mauzas, a land administrative unit. Urban areas are divided into wards and then mahallas for both surveys. A nationally representative, two-stage sample was selected from the master sample maintained by Bangladesh Bureau of Statistics. In the rural areas, the primary sampling unit was the mauza, while in urban areas it was the mahalla. A total of 341 primary sampling units were selected for the BDHS 1999-2000 survey where 99 in urban areas and 242 in rural areas. In BDHS 2004 survey, a total of 361 PSUs, 122 in the urban area and 239 in the rural area has been selected. 10,544 of ever-married women are successfully interviewed in 1999-2000 survey and 11,440 were in 2004.

\subsection{Methodology}

To identify childbearing differential we first use bi-variate analysis (chi-square test) to discover the initial factors those are related to childbearing pattern. Our null hypothesis was there was no association between childbearing pattern and the specific factor, more specifically childbearing pattern in all categories is equal for each factor. Once we have identified the factors $(p$-value $<0.05)$ from the bi-variate analysis, GLM with Poisson link function has been carried out to assess the factors. GLM with Poisson link is particularly useful for response variable that are counts or frequencies and for which it is reasonable to assume an underlying Poisson distribution (McCullagh and Nelder, 1983; Everitt, 2003); that is, the distribution

$$
\operatorname{Pr}(y)=\frac{\exp (-\mu) \mu^{y}}{y !} .
$$

For exploring the relationship between the mean of a Poisson variate and some explanatory variables of interest, the link function in a generalized linear model (GLM) is generally taken to be the logarithm, generating positive fitted values. Since the response variables here is a count, Poisson regression is used to investigate the relationship of number of children with the explanatory variables; explicitly, the model to be fitted to the mean number of children, $\mu$ is

$$
\log (\mu)=\beta_{0}+\beta_{1} X_{1}+\beta_{2} X_{2}+\ldots+\beta_{p} X_{p} .
$$

Significance test for the estimated parameters is also done in this analysis by using well-known Wald test statistics. The test statistic for the $j$ th coefficient is

$$
W_{j}=\frac{\beta_{j}}{S . E .\left(\beta_{j}\right)} .
$$

Under the null hypothesis that, $\beta_{j}$ follows standard normal distribution. The associated $p$-value is $p=\operatorname{Pr}\left[|Z|>W_{j}\right]$.

\subsection{Variables}

Dependent variable: The dependent variable for the analysis is the number of living children. 
Independent variables: Two categories of independent variable have been included for the analysis, one is individual level response and the other is demographic units. For the purpose of analysis, we have used geographic units using two different variables: region and type of places of residence. Region represents six administrative divisions -- Barisal, Chittagong, Dhaka, Khulna, Rajshahi and Sylhet. Type of place of residence has two categories - rural and urban.

At individual level we have included seven independent variables: age-group in five years, educational level, age at first marriage, media exposure and religion.

a. Age-group (in five years): Each woman's age was recorded in complete year as well as in five-year age group.

b. Education level: Educational attainment was also recoded in years of schooling completed and also in levels. The categories are -- no education (which includes never been to school and no year of schooling completed), primary (either incomplete, $0-4$ years of schooling completed or 5 years of schooling completed), secondary and higher (11 and more years of schooling completed).

c. Age at first marriage: This variable is recorded as complete years.

d. Media exposure: Media exposure was measured by asking respondents whether they listened radio or watched television.

e. Religion: Woman's religion is coded as Muslim, Hindu, Buddhist and Christians.

f. Current working status: Whether or not a woman currently working.

g. Husband's educational level: The education attainment of the husband.

h. Husband's occupation: Current occupation of husband.

\section{Results}

The frequency distribution of the number of ever-married women sampled in BDHS 1996-97 and 2004 is presented in Table 1. Among the women surveyed in 1999-2000, 12.6 percent have no child, 20.4 percent have one child and 22.4 percent have two children. In 2004, 12.2 percent have no child, 19.3 percent have one child and 23.5 percent have two children.

Table 2 shows that the mean number of children by selected background characteristics. Three variables: woman's current working status, husband's occupation and education have been dropped from Table 3 and also from further analysis since they appeared insignificant in bi-variate analysis $(p$-value $>0.05)$. For all other variable $p$-value were $<$ 0.05 . The mean number of children to women in each five-year age group, which is considered as an indicator of the momentum of childbearing, shows that women in their late twenties have given birth to almost two children and in late thirties, they have about four children. The childbearing pattern also varied by types of place of residence. In rural areas, childbearing tendency is higher than urban areas. Mean number of living children is highest in Chittagong division 2.83 and 2.84 in both surveys, while it is smallest in Khulna division 2.32 and 2.28. Childbearing is remarkably varied by the educational level of the women. The women, who have no education, bear on an average more than three children, whereas it is 1.88 for the women who have secondary education and 2.55 who have primary education according to 1999-2000 survey. The same trend retained in 2004. The higher educated women have only 1.39 children on average and the figure decreased in 2004. Age at first marriage is highly evident between the categories $<20$ and $>20$. The mean number of children is almost twice among the women who are first married at age $<20$ than among $>20$. The tendency of childbearing also varies by the religion. The hindu women tend to have the smallest families than the women of other religion. The buddhist women have on average the highest number of children, closely followed by the muslim women. Although childbearing differentials by husband's education and occupation, respondent's occupation and current working status, having radio or television etc. are not notable; but their categories vary in some extent. Since the response variable in this study is a count data, a GLM with Poisson link is used to model for identifying the significant factors.

The graph in Fig. 3 also suggests a typical Poisson curve with mean $\mu>1$. The results of the fitted model are presented in Table 3. The $p$-values in the above table show that all the explanatory variables are highly significant. The coefficients of 5-year age groups show a declining trend, indicates that childbearing decreases as age increases to the women in Bangladesh. The earlier age at first marriage causes more children bearing to the women. This study also demonstrates that division is significant in childbearing. The coefficient of Khulna division has the lowest value, followed by Dhaka. Chittagong and Sylhet division have the higher value in comparison to Barisal division. Both surveys show that Khulna has the lowest level of fertility and highest level of contraceptive use rate, whereas the lowest level of contraceptive use in found in Sylhet division.

These results might be the cause of childbearing differential by division. The place of residence is also found to be significant in childbearing. The coefficient of the category urban has a negative value. This implies that place of 
residence in urban areas has a negative impact on childbearing rather than that of rural areas. Childbearing differentials by educational level of the mothers and age at first marriage are obtained to be notable as key indicators. It is found that the childbearing drastically varies by the educational levels of the mothers. The estimated coefficients show declining trend with the level of education to the women, which reveals those who become more educated, bearing fewer children Another significant factor, which is considered as an important determinant of childbearing, is the age at first marriage. The coefficient estimated to be negative implies that rate of childbearing decreased with the age at first marriage. The results shown in the above table also indicate that religion, husband's occupation, having radio or television (medie exposure) are also important determinants of childbearing among the ever-married women in Bangladesh.

\section{Discussion and policy implication}

This study has tried to demonstrate the different key issues of childbearing in Bangladesh. The fitted model suggests that mother age group is a determinant of more childbearing. Childbearing at early ages is a common phenomenon in Bangladesh. It was found that adolescent childbearing is highest in Bangladesh among Asian countries, which also happens in sub-Saharan African countries (Singh, 1998). Among the divisions, women in Sylhet and Chittagong have the greater mean number of living children. In these divisions contraceptive use rate is comparatively low. The educational levels of the mothers are found to be the key factor of bearing more children in Bangladesh. The women who have no education are more likely to bear more children than higher educated of secondary completed mothers. Residence in rural areas is also causes for more childbearing. Early age at first marriage has an obliging effect on childbearing. The overall mean and median age at first marriage are 15 and 14 respectively. In rural areas, a significant number of females are married when they are only 10-12. This is one of the main reasons of more childbearing to the Bangladeshi women. The mean number of children among the women whose age at first marriage was $<20$ is 2.61 whereas the mean is 1.45 for the women who were married at age $>20$. So childbearing could be reduced by increasing the female age at first marriage to 20 years. However, in recent years, the mean age at first marriage in Bangladesh though a very slow rate but increasing in somewhat extent. Religion and media exposure are also appeared to be important as determinants of childbearing. This study confirms that there is not much change observed over past five years from 2000 to 2004 in term of reducing child bearing. The trend of the effects of typical demographic and socio-economic factors on childbearing pattern among the women in Bangladesh does not show a substantial change. Therefore, appropriate policy and programs should be driven immediately to reduce the level of childbearing in consideration to the existing higher rate of childbearing among the women in Bangladesh. The women and their husbands should be made more aware of the adverse effect on health, social and economic consequences of early marriage and early childbearing. The educated women have taken the small family norm in recent years. So government should give emphasis on female education. Since there is a moderate gender gap in enrolment, female education has to be encouraged particularly in the rural areas. Also urbanization should be progressed and the facilities of communication, electricity and the scope of employment are to be increased. More childbearing tendency could be brought to a decline by delaying early marriage. To discourage early marriage and to explain the perilous consequences of bearing more children among the mothers, variety of programs in this regard should be broadcasted through the electronic and print media. In fact government should take all necessary steps to reduce the level of more childbearing. However, this study considers only 1999-2000 and 2004 BDHS data. It will be more interesting to incorporate the same analysis for 2006 data and derive the trends and substantial changes of the relevant factors if any exists when the data will be available.

\section{References}

Asaduzzaman, M. \& Ullah, M. S. (2003). Desire for More Children in Bangladesh: Evidence from BDHS 1999-2000. Social Science Review, The Dhaka University Studies, Part-D, 20, 149-159.

BBS (1999). Statistical Year Book 1999, Bangladesh Bureau of Statistics: Ministry of Finance and Planning.

Everitt, B. S. (2003). Modern medical Statistics, London: Arnold.

Islam, M. M. (1999). Adolescent childbearing in Bangladesh, Asia-Pacific Population Journal, 14, 73-87.

Islam, M. N., Mamun, A. A. \& Bairagi, R. (1998). Fertility and its proximate determinants in Bangladesh: evidence from the 1993-94 Demographic and Health Survey, Asia-Pacific Population Journal, 13, 3-22.

Islam, M. N. \& Islam, M. M. (1993). Biological and behavioural determinants of fertility in Bangladesh:1975-1989, Asia-Pacific Population Journal, 8, 3-18.

Manken, J., Duffy, L. \& Kuhn, R. (2003). Childbearing and women's survival: New evidence from rural Bangladesh, Population and Development Review, 29, 405-426.

McCullagh, P. \& Nelder, J. A. (1983). Generalized Linear Models, London: Chapman \& Hall.

Mitra, S. N. et al. (2000). Bangladesh Demographic and Health Survey 1999-2000, NIPORT, Dhaka, Bangladesh.

Mitra, S. N. et al. (2000). Bangladesh Demographic and Health Survey 2004, NIPORT, Dhaka, Bangladesh. 
Nahar, K. \& Min, H. (2008). Trends and Determinants of Adolescent Childbearing in Bangladesh, DHS working paper, No. 48 .

Rob, A. K. U. (1990). Determinants of fertility in Bangladesh, Biology and Society, 7, 31-37.

Singh, S. (1998). Adolescent childbearing in developing countries: A global review, Studies in Family Planning, 29, 117-136.

Schuler, S. R., Bates, L. M., Islam, F. \& Islam, M. K. (2006).The timing of marriage and childbearing among rural families in Bangladesh: Choosing between competing risks, Social Science \& Medicine, 62, 2826-2837.

Table 1. Total number of ever-married women sampled (unweighted) by age groups

\begin{tabular}{l|r|r}
\hline Age group & \multicolumn{1}{|c|}{$1999-00$} & \multicolumn{1}{|c}{2004} \\
\hline $10-14$ & 186 & 140 \\
$15-19$ & 1,514 & 1,563 \\
$20-24$ & 1,935 & 2,202 \\
$25-29$ & 1,975 & 2,012 \\
$30-34$ & 1,621 & 1,783 \\
$35-39$ & 1,335 & 1,480 \\
$40-44$ & 1,126 & 1,185 \\
$45-49$ & 853 & 1,075 \\
\hline Total & 10,540 & 11,440 \\
\hline
\end{tabular}

Table 2. Mean number of children by selected background characteristics in survey period 1999-2000 and 2004

\begin{tabular}{|c|c|c|}
\hline Characteristics & $\begin{array}{l}\text { Mean Number of } \\
\text { Children in 1999-2000 }\end{array}$ & $\begin{array}{l}\text { Mean Number of } \\
\text { Children in } 2004\end{array}$ \\
\hline \multicolumn{3}{|c|}{ Age 5-year groups } \\
\hline $10-14$ & 0.10 & 0.04 \\
\hline $15-19$ & 0.69 & 0.67 \\
\hline $20-24$ & 1.54 & 1.54 \\
\hline $25-29$ & 2.36 & 2.38 \\
\hline $30-34$ & 3.11 & 3.06 \\
\hline $35-39$ & 3.54 & 3.50 \\
\hline $40-44$ & 4.12 & 3.85 \\
\hline $40-49$ & 4.87 & 4.48 \\
\hline \multicolumn{3}{|c|}{ Types of place of residence } \\
\hline Urban & 2.33 & 2.32 \\
\hline Rural & 2.65 & 2.61 \\
\hline \multicolumn{3}{|l|}{ Region } \\
\hline Barisal & 2.71 & 2.73 \\
\hline Chittagong & 2.83 & 2.84 \\
\hline Dhaka & 2.53 & 2.50 \\
\hline Khulna & 2.32 & 2.28 \\
\hline Rajshahi & 2.52 & 2.40 \\
\hline Sylhet & 2.82 & 2.81 \\
\hline
\end{tabular}




\begin{tabular}{l|l|l}
\hline & & \\
\hline Highest educational level & & 3.17 \\
\hline No education & 3.04 & 2.60 \\
Primary & 2.55 & 1.67 \\
Secondary & 1.88 & 1.27 \\
Higher & 1.39 & \\
\hline & & \\
\hline Age at First Marriage & & 2.61 \\
\hline$<20$ & 2.66 & 1.45 \\
$>=20$ & 1.61 & \\
\hline & & 2.64 \\
\hline Media exposure & & 2.36 \\
\hline No & 2.66 & \\
Yes & 2.45 & \\
\hline & & 2.56 \\
\hline Religion & & 2.35 \\
\hline Buddhism & 2.61 & 1.92 \\
Christianity & 2.41 & 2.71 \\
Hinduism & 2.33 & \\
Islam & 2.82 & \\
\hline & & \\
\hline & & \\
\hline & & \\
\hline & & \\
\hline & & \\
\hline & & \\
\hline & & \\
\hline & & \\
\hline & & \\
\hline & & \\
\hline & & \\
\hline
\end{tabular}

Table 3. Results of the fitted regression model

\begin{tabular}{l|c|c|c|c}
\hline Characteristics & \multicolumn{2}{|c|}{ BDHS 1999-2000 } & \multicolumn{2}{c}{ BDHS 2004 } \\
\hline Age 5-year groups & Coefficients & $p$-values & Coefficients & $p$-values \\
\hline $10-14$ & 2.02 & 0.000 & 2.49 & 0.000 \\
$15-19$ & 2.84 & 0.000 & 3.39 & 0.000 \\
$20-24$ & 3.28 & 0.000 & 3.81 & 0.000 \\
$25-29$ & 3.55 & 0.000 & 4.06 & 0.000 \\
$30-34$ & 3.65 & 0.000 & 4.17 & 0.000 \\
$35-39$ & 3.78 & 0.000 & 4.25 & 0.000 \\
$40-44$ & 3.93 & 0.000 & 4.36 & 0.000 \\
$40-49$ & $*$ & $*$ & $*$ & $*$ \\
\hline & & & & \\
\hline Region & & & & 0.000 \\
\hline Barisal & 0.12 & 0.000 & 0.10 & 0.001 \\
Chittagong & -0.01 & 0.604 & -0.06 & 0.000 \\
Dhaka & -0.07 & 0.004 & -0.15 & 0.000 \\
Khulna & -0.02 & 0.357 & -0.12 & 0.000 \\
Rajshahi & 0.07 & 0.006 & 0.09 & $*$ \\
Sylhet & $*$ & $*$ & $*$ & \\
\hline & & & & \\
\hline Types of place of & & & & \\
residence & & & & \\
\hline & & & & \\
\hline
\end{tabular}




\begin{tabular}{|c|c|c|c|c|}
\hline Urban & 0.06 & 0.000 & 5.653 & 0.000 \\
\hline Rural & $*$ & $*$ & $*$ & $*$ \\
\hline \multicolumn{5}{|c|}{$\begin{array}{l}\text { Highest educational } \\
\text { level }\end{array}$} \\
\hline No education & 0.02 & 0.067 & 1.391 & 0.164 \\
\hline Primary & -0.08 & 0.000 & -5.184 & 0.000 \\
\hline Secondary & -0.32 & 0.000 & -7.483 & 0.000 \\
\hline Higher & $*$ & $*$ & $*$ & $*$ \\
\hline \multicolumn{5}{|c|}{ Age at First Marriage } \\
\hline$<20$ & -0.04 & 0.000 & -22.11 & 0.000 \\
\hline$>=20$ & * & $*$ & $*$ & $*$ \\
\hline \multicolumn{5}{|c|}{ Media exposure } \\
\hline No & -0.01 & 0.25 & -2.90 & 0.003 \\
\hline Yes & $*$ & $*$ & $*$ & $*$ \\
\hline \multicolumn{5}{|l|}{ Religion } \\
\hline Buddhism & -0.13 & 0.000 & -5.49 & 0.000 \\
\hline Christianity & -0.18 & 0.011 & -1.82 & 0.067 \\
\hline Hinduism & -0.15 & 0.184 & -0.17 & 0.861 \\
\hline Islam & $*$ & $*$ & $*$ & $*$ \\
\hline
\end{tabular}

\section{* Reference category}

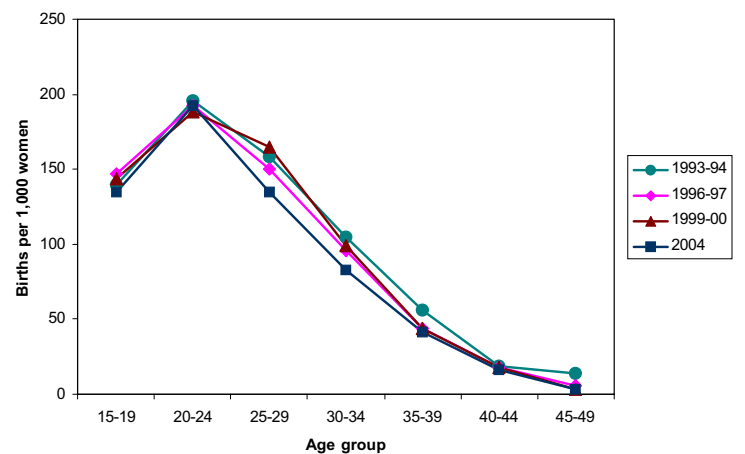

Figure 1. Age-specific fertility rates in Bangladesh during 1993-2004 


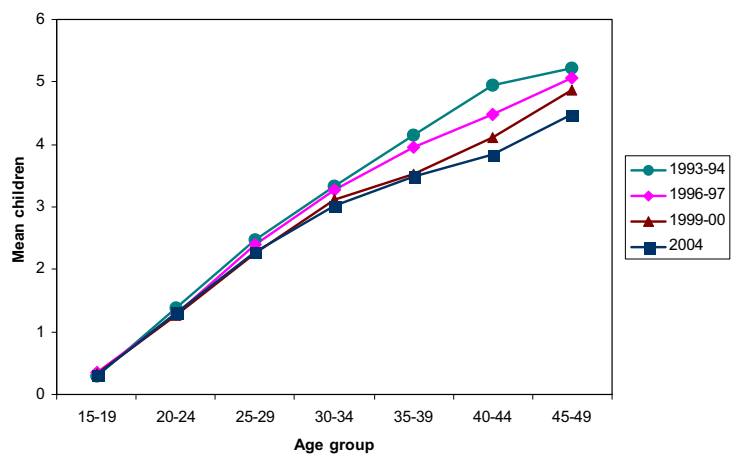

Figure 2. Age-specific mean number of children in Bangladesh during 1993-2004
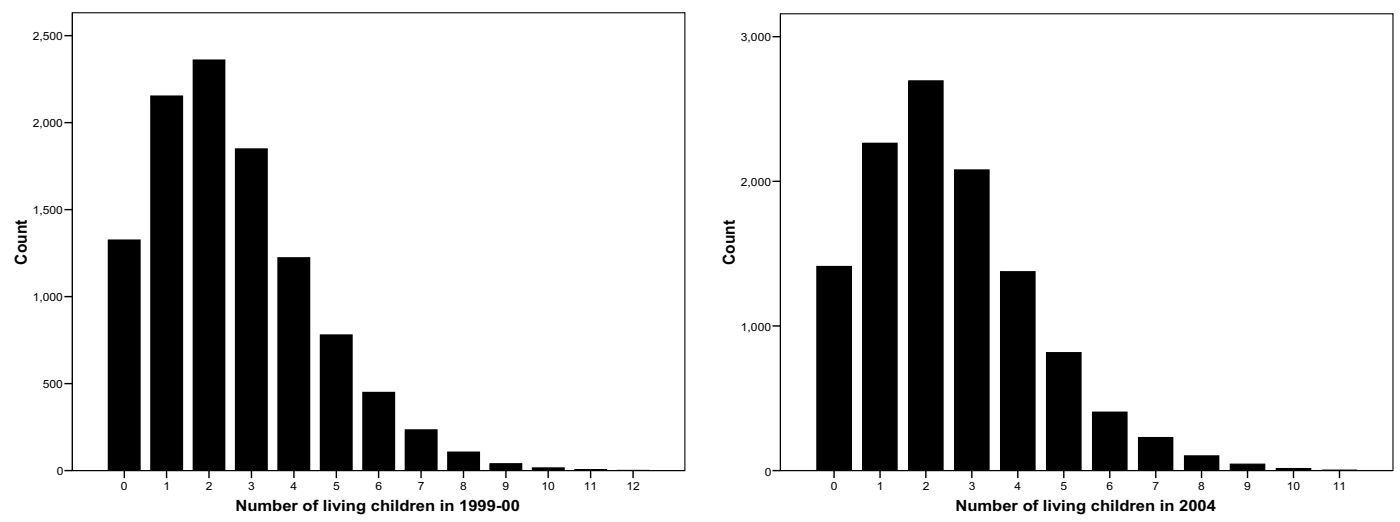

Figure 3. Distribution of number of living children in 1999-00 and 2004 